\title{
FORM FOLLOWS STORY: AN APPROACH TO DESIGNING FOR COMMERCIAL SPACE TRAVEL
}

\author{
Jason GERMANY ${ }^{1}$ and Justin LUND ${ }^{2}$ \\ ${ }^{1}$ Industrial Design Programme - University of Washington \\ ${ }^{2}$ Division of Design - University of Washington
}

\begin{abstract}
Designers are increasingly taking on the role of future forecaster. As a result, the problem of future framing and designing for experiences that have not yet materialised is something that educators are beginning to introduce into regular design and engineering curriculum. This paper disseminates an approach to designing for this emerging future through an industry collaborative course that explored commercial space travel for the year 2030. To approach the intangible experience of space travel, students were challenged to consider activities and environments that were far removed from their everyday experiences. Unlike some traditional user-centred research methods, this course asked students to develop their own empathic and immersive research methods. These methods were then leveraged to develop journey stories as a launching point for the actual design concepts. Coupling these two problems framing strategies of empathic immersive research and storytelling exposed both benefits and some challenges.
\end{abstract}

Keywords: Space travel, speculative design, storytelling, empathic research

\section{INTRODUCTION}

Designers have long embraced uncertainty as a profession. Even seemingly simple design problems are often revealed to be a complex network of contingencies, unknowns and ambiguity. Increasingly, these problems may not be addressed through new and novel material objects but may result in a myriad of possible designed services, systems or social solutions. These wicked problems [1] are compounded by the many solutions relevant to the present moment, as well as the activity of planning for the possible implications of these solutions in the future. Historically, designers have a strong foundation of looking towards the past for precedent, reason and trajectory, yet today's designers need an ability to visualise the future. Iterative approaches to problem solving and a desire to develop these alternatives into a final concept are the underlying structure of the design process. Based on that, designers are increasingly taking on the role of future forecaster. Design discourse surrounding future forecasting has traditionally referred to these efforts as critical design [2], design fiction [3], and speculative design [4] amongst others. For the purposes of this discussion, speculative design most closely embodies the activities outlined in this paper and the resulting studio class case study.

Contemporary efforts to envision future scenarios are growing in practice. Consequentially, design education is challenged to find appropriate methods to address and prepare students for a role in envisioning the future. A part of this challenge is to create a platform that positions students to exercise their speculative faculties yet is tangible enough to the present moment to be accessible. Space travel, particularly commercial space travel, is one such platform. This represents a promising design education domain [5] and one that will increasingly leverage speculative means. Very soon, everyday consumers will have the ability to travel not only into the low gravity of the Earth but onward to space hotels, moon bases and possibly even Mars. Space tourism is balanced between the speculation of unknown future scenarios and the tangible practicality of a rapidly emerging market. This paper reports on one such effort as students in an industrial design studio course were given the challenge to design for this emerging future through an industry collaborative course that explored commercial space travel for the year 2030 . 


\section{BACKGROUND - COMMERCIAL SPACE TRAVEL}

Early missions into space were large government funded initiatives that supported the efforts of a select few individuals to go into space and report back about their discoveries. Recently, there has been a surge in interest in the private space sector producing such visible players as Virgin Galactic, SpaceX, and Blue Origin [6]. Boeing and Space Adventures have planned to offer a commercial passenger options to the International Space Station (ISS) aboard the new CST-100 Starliner capsule [7]. These efforts mark the dawn of space tourism where humans will be able to stay in space hotels, travel to the moon, and beyond. This also represents a shift towards an area of tourism that has no historic examples to drawn from and subject's tourists to environments and experiences that no designer has ever had nor has the ability to directly reflect upon. This represents an opportunity for designers to consider how empathic and narrative methods might inform these new experiences.

Historically, design for space has been a technical endeavour. As Mary Roach says in Packing for Mars, "To the rocket scientist, [humans] are a problem. [They] are the most irritating piece of machinery he or she will ever have to deal with." [8]. Much like the vehicle design of military equipment and naval architecture, the human is often considered after all other constraints have been met. Often, the facilities meant for the actual crew are developed to meet the bare minimum of accepted codes and wedged in wherever space allows. Space missions are no exception. With the added constraint of incredible fuel costs, the smaller the payload the better. The shift from state sponsored space travel to space tourism marks a shift from a purely scientific / military activity to a more experiential one necessitates that the needs of the crew and tourist take on a larger role. As a result, there has been an increase in the involvement of design agencies in the creation and conception of these new travel experiences. An example of one such engagement is the partnership outline in this paper between the design firm TEAGUE and the University of Washington (UW) industrial design programme.

As a leader in aviation design field, TEAGUE was interested in exploring possibilities in this emergent form of travel. For over 70 years TEAGUE has worked with Boeing to envision the future of flight [9]. In August 1993, NASA selected Boeing as the main contractor for the construction of the International Space Station (ISS). The ISS began a new chapter in the design process for space because the ISS would facilitate long-term habitation, and as a result, additional considerations had to be taken for the mental and physical well-being of its inhabitants. TEAGUE worked with Boeing on the design of the Habitat Module [10] so a partnership with UW to explore concepts for a commercial space journey was a natural fit. As a result of this industry partnership, a studio class was constructed around this theme and focused on the development of interior space craft concepts and the resulting narratives that supported these commercial space scenarios.

\section{STUDIO: MISSION TO THE MOON (M2M 2030)}

\subsection{Course structure and implementation}

The studio class was structured on a single project and team-based work spread across the quarter with individual deliverables contributing to the overall performance of the group's work. To best support the various research and design activities over this 11 week term, the 20 industrial design students in the class were broken into teams of four. The class met in a studio style format twice a week for three hours each meeting. These two meetings were initially split each week between a range of activities including TEAGUE (sponsor) studio tours, lectures, and workshops as a means of accelerating students into the research collection phase. In addition to these activities, students also engaged in select readings from the books "Packing for Mars" [8] and "Riding Rockets" [11] as a primer and background to the problem of habitat in space. This initial phase of priming the student teams for the topic had two primary goals; 1. Provide a short outline of personal experiences of astronauts through readings and 2. Expose them to mapping techniques that they could utilise to frame a future scenario. As the students would not have direct contact with anyone that had spent time in space, these two aims provided for just enough literacy on the topic. Coupled with these techniques was an audit of current trends in state sponsored and commercial space travel combined with the elements commonly found in traditional adventure tourism. As many researchers have reported on the importance of introducing empathic methods into design curriculum [12] [13], the goal of these kick-off efforts was to position the teams with enough knowledge to frame their own empathic research experiments. The students were tasked with devising their own experiments that examined the challenges of 1. Isolation from Earth and 2. Operating in constrained or weightless spaces. Isolation is a part of space travel (Stuster, 2010) and being separated from the Earth. 
As such, the teams devised isolation studies with multiple or individual participants from the group involved. Spatially constrained and weightless tasks are also a ubiquitous part of space travel. The objective was to understand how being confined in a small space with other people might affect individuals and ultimately their design. In approaching this study, teams picked a daily task and tried to emulate that in a constrained location. Overall, these research and problem-framing activities were a series of methods to support storytelling as an initial design concept into the future of commercial space travel. The narrative design [15] tools at play were service oriented and a combination of journey mapping and storyboarding [16].

\subsection{Student team examples: Empathic isolation and constraint studies}

Five student teams executed a series of empathic and immersive studies of their own design. The individual studies of each exercise have been abbreviated for the sake of reporting in this paper and to reduce any redundancy between team approaches. In general, the study plans that the teams developed broke into five main types: 1. individual isolation(s), 2. team isolation(s), 3. individual constrained tasks, 4. team constrained tasks and 5. observations of constrained individuals in public environments. Examples of individual isolation commonly took the form of a single student sequestering themselves in a room or apartment away from digital and verbal distractions for an extended period of time; in some cases, this experiment was repeated over several days and the student recorded experiential challenges related to this isolating experience. Team isolations were coordinated, timed ( $3 \mathrm{hr}$ or more) and often coincided with a confined space without windows. These studies recorded group interactions and the effects of no outside stimuli. Individual constrained tasks were short exercises that tested common tasks like getting shoes on and off while limiting the spatial area to complete this task. Several individuals utilised a sleeping bag as their confining element. Team constrained tasks ranged for group exercises like the 'human puzzle' or other games where individuals had to coordinate their efforts to a single goal (figure 1). Additionally, teams utilised submersion in swimming pools to emulate weightless and performed tasks like Lego assembly or changing and folding clothing (figure 1). Lastly, groups went to crowded public places and public transit to observe non-team members and how individuals interacted spatially in these confined locations.

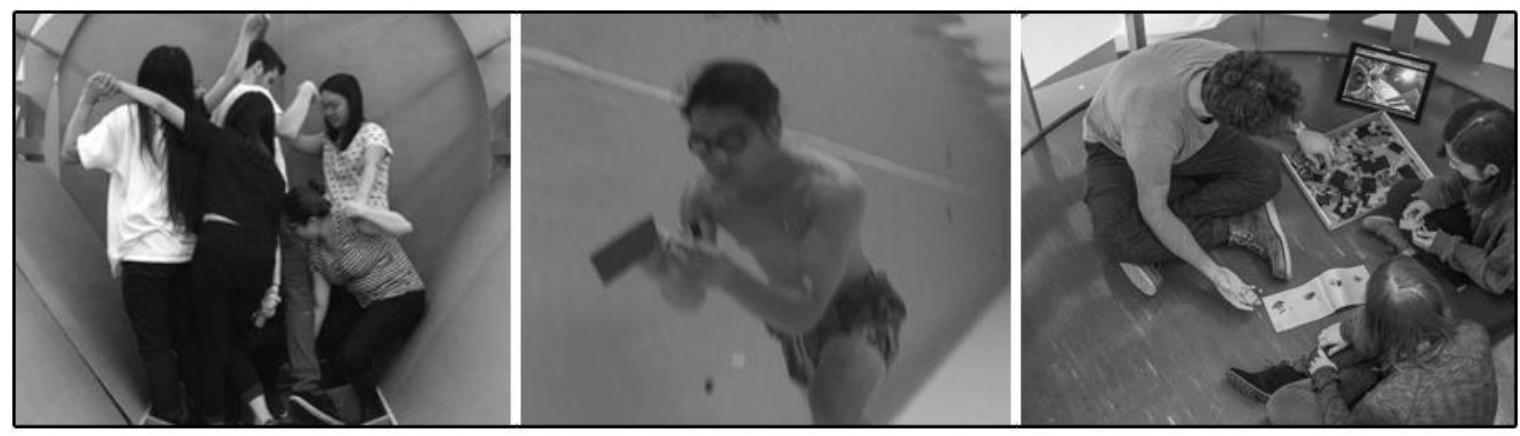

Figure 1. Sample immersive and constraint student studies

Ultimately, these experiential studies were utilised as a way of highlighting potential pain points that may exist in space travel. Although they were not direct emulations of what astronaut's experience, they provided insights into the fundamental challenges that confined environments have on interpersonal relationships as well as daily tasks. These insights were leveraged as a starting point for the next phase of the design and ideation portion of the project.

\subsection{Student team examples: Journey Maps and Storyboards}

After the preliminary steps of secondary data collection and empathic and constraint studies, the teams started their concept development utilising storytelling methods as a means of mapping out the overall journey. As a constraint, teams were asked to conceive a seven-day space journey within the cislunar area that started from Earth orbit, travelled out and past the Moon and returned to Earth orbit for the year 2030. This journey would be supported by three crew members and four passengers (tourists). In doing so, teams had to envision service-based experiences with unique touch points within the interior of the space vehicle. Additionally, the envelope of the vehicle interior was defined for teams. Although these missions would not involve a lunar landing, for the initial mapping exercise students mined data 
on previous Apollo missions including the daily activities of astronauts as a starting point for their proposed activities. These activities were then adjusted to better support the relationship between passenger (tourist) and crew members. Lastly, they were asked to utilise their insights from isolation and constraint studies to map out potential pain points along the journey and infer the emotional impact this might have on both the passengers and crew members (figure 2).

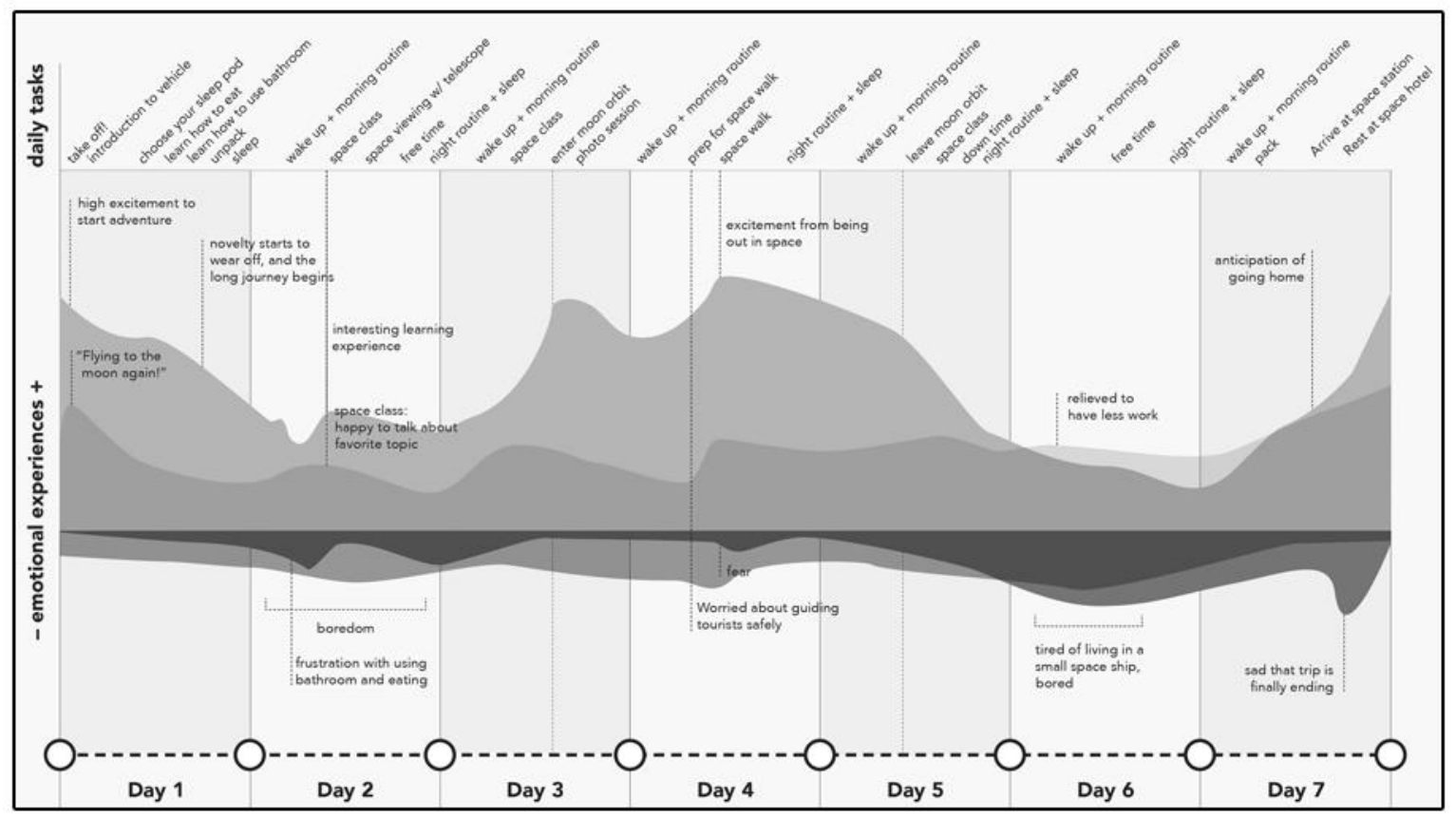

Figure 2. Sample of student team journey mapping

After developing the structure of the seven-day space mission, teams were then asked to convert that to a more accessible visual story that highlighted unique experiences that their team envisioned throughout the journey. This process started with a brainstorming session that generated several scenarios with each of these aimed at elevating important moments each day. Students then down selected the most promising events and generated a set of sketched tiles (figure 3) that were used to present their proposed journey before advancing to the next phase of design.

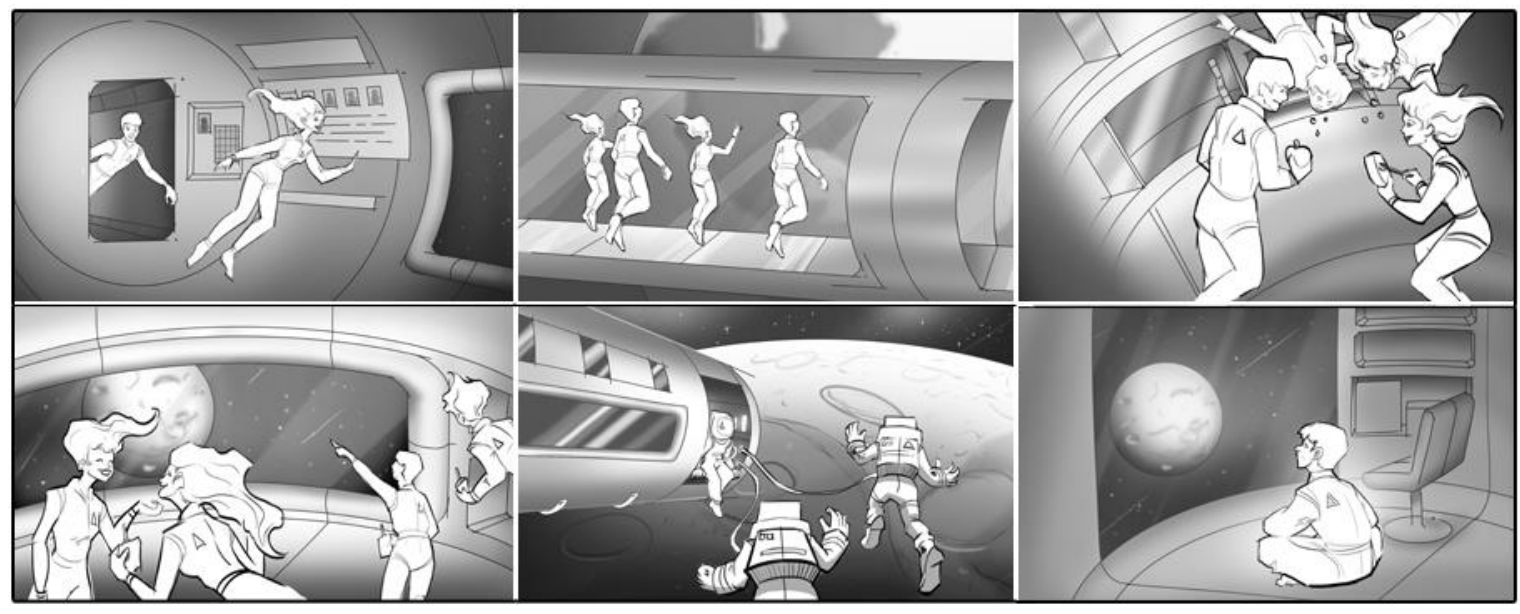

Figure 3. Sample of student team storyboarding

\section{Discussion}

The results of the student activities were primarily collected by faculty observations as well as input from liaison designers from the studio sponsor TEAGUE. Faculty observations and interactions occurred during regular class meetings throughout the quarter; specifically, twice a week for three hours each meeting. Faculty summary review and discussion with the corporate sponsor liaison designers 
evaluated the success or failure of teaching strategy and occurred informally on a weekly basis and formally at the end of the term. Additional student feedback occurred verbally throughout the term but was complemented by a course evaluation with summary notes on the class. The main points based on these observations and feedback are highlighted in the following sections.

The overall approach to the course was structured around storytelling as a platform for enabling empathy as well as concept development and refinement. This approach has benefits that apply to courses beyond those focused on commercial space travel and those benefits translate to three main activities; 1 . planning, 2. iteration and 3. final communication. The 'planning' benefits observed were two-fold. First, the storytelling components enabled both speculative and strategic thinking. Students were challenged to take a strategic position about this future and intangible experience which leads to the second 'planning' benefit - defining boundaries. Appling fictional characters and experiences across a timeline required students to create bounded rationalities [17] within the problem space and ultimately define many of their own design constraints. The 'iteration' portion of the project also had two primary benefits from this approach. The story helped to select the most important tangible interior touchpoints related to their defined journey. These touchpoints ranged from elements like dining areas or an observatory spaces but were uniquely connected to the scene of their story, converting abstractions to tangible prototypes. The second benefit was that as the interior design evolved, the scenario evolved and was renegotiated. The story they told at the beginning of the class through journey mapping and storyboarding was both 'concept' and 'research synthesis'. This give and take between ideal future and tangible constraints (prototypes) was a form of reframing the problem in parallel with the solution alternatives or a co-evolution [18]. The 'final communication' benefits were primarily associated with the delivery of the final design to people outside of the design team. The updated storyboard was utilised as a scenario by which the student teams explained the connection between tangible interior designs and the overall experience.

One of the primary instructional challenges observed from this approach was providing enough constraints to facilitate a boundary for students to work with in while allowing them enough latitude to take a novel strategic position in their proposed future scenario. Moving forward, this presents a fine line for instructors to negotiate working within this speculative space when defining the boundaries and scope of work.

\section{CONCLUSIONS}

Designers are increasingly taking on the role of future forecaster. Situated between contemporary problems and speculative ones, designers must continue to leverage new platforms for exploring this unknown future. As a result, educators are increasingly introducing these challenges into the classroom and new studio formats. In the industry collaborative studio outlined in this paper, the topic of commercial space travel served as a unique domain to explore a range of empathic and immersive research methods. As a result, students were tasked with conceiving their own approach to these research methods which functioned as a jumping off point for storytelling. This storytelling approach has benefits that apply to courses beyond those focused on commercial space travel and those benefits translate to three main activities; 1 . planning, 2. iteration and 3. final communication. In doing so, students were forced to take a strategic position about a future scenario, craft the constraints around that future and support the research synthesis and final concept through tangible touch points. The story became the concept and the interior design was its embodiment. The challenge for instruction and course planning exists in how tightly the boundaries are placed on the class at the beginning of the term. Enough boundary definition is needed to facilitate basic deliverables and focus student effort, while not so much as to inhibit the story and strategic position of the student teams.

\section{ACKNOWLEDGEMENTS}

The studio project highlighted in this paper was made possible with the generous donation of time and expertise from TEAGUE Aviation Studio. The success of this studio would not have been possible without their contribution. Additionally, acknowledgement goes to the student work examples highlighted in this paper and contributed by Nate Chang, Carly Cheng, Casey Gustafson, Max Werner, Izabella Dadula, Ryan Gilmore, Jazmine Hoyle, and Wei Li. 


\section{REFERENCES}

[1] Rittel H.W.J. and Webber M.M. Dilemmas in a General Theory of Planning. Policy Sciences, vol. 4, no. 2, 1973, pp. 155-169.

[2] Dunne A. 'Hertzian Tales': An Investigation into The Critical Potential of Electronic Product as a Post-Optimal Object. PhD Dis. Lon, RCA, London, 1997.

[3] Sterling B. Shaping things, Cambridge, Mass: MIT Press, 2005.

[4] Dunne A. and Raby F. Speculative Everything: Design, Fiction, and Social Dreaming. Cambridge, Massachusetts: MIT Press, 2013.

[5] Ledsome C. Student Design Projects Set in the Space Environment, in International Conference on Engineering and Product Design Education, Oslo, 2017.

[6] Prosser M. 5 Space Companies Zeroing in on First Launch of Tourists into Orbit and Beyond, 10 May 2018. [Online]. Available: https://singularityhub.com/2018/05/10/5-space-companieszeroing-in-on-first-launch-of-tourists-into-orbit-andbeyond/\#sm.0000uh284k666d0ftzl2kncv81879.

[7] Experiences: Space Station, 2018. [Online]. Available: http://www.spaceadventures.com/experiences/space-station/.

[8] Roach M. Packing for Mars: The Curious Science of life in the Void, New York: W.W. Norton, 2010.

[9] Teague + Boeing, 2014. [Online]. Available: https://vimeo.com/87512096.

[10] Rocket Science: Lessons from Designing for Space Travel, March 2018. [Online]. Available: http://labs.teague.com/?p=2441.

[11] Mullane M. Riding Rockets: The Outrageous Tales of a Space Shuttle Astronaut, New York: Scribner, 2007.

[12] Malins J. and McDonagh D., A Grand Day Out: Empathic Approaches to Design," in International Conference on Engineering and Product Design Education, Barcelona, 2008.

[13] Feng J. Cultivating Creativity through Empathising: An Empathy Focused Framework in Design Studio Teaching, 2017.

[14] Stuster J. Behavioural Issues Associated with Long Duration Space Expeditions: Review and Analysis of Astronaut Journals Experiment 01-E104 (Journals): Final Report," NASA, Houston, 2010.

[15] Cooper A., Reimann R. and Cronin D. About face 3: the essentials of interaction design, Indianapolis: Wiley, 2007.

[16] Stickdorn M. and Schneider J. This is Service Design Thinking: Basics, tools, cases, Hoboken: Wiley, 2011.

[17] Simon H. The Sciences of the Artificial - 3rd Ed., Cambridge: MIT Press, 1996.

[18] Dorst K. and Cross N. Creativity in the design process: co-evoluation of problem-solution, Design Studies, pp. 425-437, 2001. 